
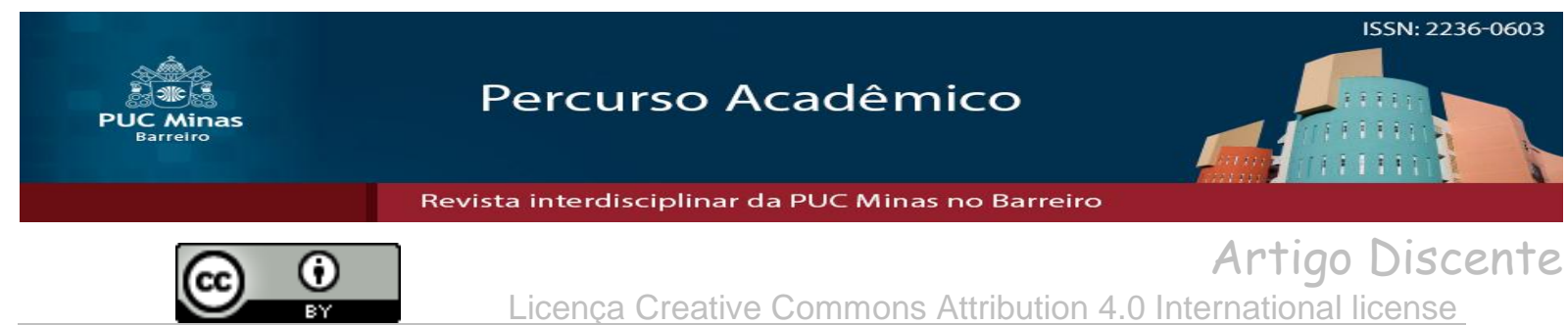

Licença Creative Commons Attribution 4.0 International license

\title{
O modelo constitucional do processo no novo Código de Processo Civil e a possibilidade de negociação dos atos processuais
}

\section{The constitutional model of the process in the new Civil Process Code and the possibility of trading of the procedural acts}

Marcelo Lucas Ribeiro de Oliveira ${ }^{1}$

\begin{abstract}
Resumo
O presente trabalho tem como objetivo principal investigar a possibilidade, bem como a legitimidade da negociação dos atos processuais, prevista no artigo 190 da Lei 13.105/15, o que, em tese, permite que todo e qualquer ato processual seja objeto de deliberação entre as partes, podendo ser determinado alterações no procedimento pela vontade das mesmas. Sendo o processo constitucional uma garantia do exercício dos direitos fundamentais, surge a seguinte questão: a possibilidade de se alterar o procedimento não estaria diminuindo ou ao menos colocando em risco essa garantia? Para responder a essa questão a investigação se inicia pela exposição do que é o processo constitucional, como esse paradigma se formou, qual a sua matriz teórica, sua relação com o Estado Democrático de Direito e por fim sua legitimação expressa no Novo Código de Processo Civil brasileiro. Percorrendo esse caminho teórico pretende-se demonstrar os riscos que se cria com a possibilidade da negociação dos atos processuais.
\end{abstract}

Palavras-chave: Direitos fundamentais. Processo constitucional. Atos processuais.

\begin{abstract}
The main objective of this paper is to investigate the possibility and legitimacy of the negotiation of procedural acts, provided for in article 190 of Law 13,105 / 15, which, in theory, allows any and all proceedings to be deliberated between the Amendments to the procedure may be determined by their will. Since the constitutional process is a guarantee of the exercise of fundamental rights, the following question arises: the possibility of changing the procedure would not be diminishing or at least jeopardizing this guarantee? In order to answer this question, the investigation begins with an exposition of the constitutional process, how this paradigm was formed, what its theoretical matrix is, its relationship with the Democratic State of Law, and finally its legitimacy expressed in the New Code of Civil Procedure Brazilian. Going along this theoretical path intends to demonstrate the risks that are created with the possibility of negotiating the procedural acts.
\end{abstract}

Keywords: Fundamental rights. Constitutional process. Process acts.

Artigo recebido em 15 de Novembro de 2016 e aprovado em 21 de Março de 2018.

${ }^{1}$ Graduado em Direito pela Faculdade Novos Horizontes, pós graduando em Direito Processual pela PUC Minas e advogado. E-mail: marcelolucasro@ gmail.com. 


\section{Introdução}

A partir de 1988, com a promulgação da atual Constituição é estabelecido no Brasil o Estado democrático de Direito. Sob essa matriz principiológica se constrói o atual paradigma jurídico político, em que todo o ordenamento jurídico deve estar em consonância com a Constituição, respeitando, principalmente, os Direitos e Garantias Fundamentais, esculpidos, preponderantemente, no Artigo $5^{\circ}$ da Constituição da República Federativa do Brasil.

Dessa forma, é possível afirmar que não só o direito material precisa estar em harmonia com a Constituição, mas é imperioso que as normas de Direito Processual também estejam, pois todo e qualquer procedimento que tenha como objetivo a discussão de direitos precisa respeitar e efetivar os direitos fundamentais. Nesse diapasão é possível perceber que o artigo 190 do Novo Código de Processo Civil², ao permitir a negociação dos atos processuais, abre a possibilidade de desrespeito e não efetivação dos direitos fundamentais. Vejamos a grafia do referido artigo:

Art. 190. Versando o processo sobre direitos que admitam auto composição, é lícito às partes plenamente capazes estipular mudanças no procedimento para ajustá-lo às especificidades da causa e convencionar sobre os seus ônus, poderes, faculdades e deveres processuais, antes ou durante o processo.

Parágrafo único. De ofício ou a requerimento, o juiz controlará a validade das convenções previstas neste artigo, recusando-lhes aplicação somente nos casos de nulidade ou de inserção abusiva em contrato de adesão ou em que alguma parte se encontre em manifesta situação de vulnerabilidade.

Embora se vislumbre vários benefícios em potencial, também se percebe possíveis equívocos na aplicação de tal dispositivo, pois ao se permitir que o Estado atue na prestação jurisdicional sem a estrita observância da Lei, é uma clara afronta às garantias constitucionais previstas no artigo $5^{\circ}$, inciso LIV, da Constituição da República: “Art. $5^{\circ}$... LIV - ninguém será privado da liberdade ou de seus bens sem o devido processo legal".

Dessa forma, é possível vislumbrar a possibilidade de abuso de poder, tanto do Estado (na atuação do magistrado), bem como de uma das partes em detrimento da parte hipossuficiente. Assim, surge a indagação se a referida prática não estaria a prejudicar a garantia do exercício dos direitos fundamentais e deste modo retirando do processo sua legitimidade.

\section{Processo Constitucional}

Antes de se discutir a legitimidade do referido dispositivo legal é necessário dissertar sobre o processo constitucional, ou modelo constitucional do processo, para que assim se

\footnotetext{
${ }^{2}$ Lei $13.105 / 2015$.
} 
compreenda com clareza o paradigma processual que se tem como pressuposto para o presente estudo.

Com a promulgação da Constituição de 1988, o Brasil passa a um período efetivamente democrático ${ }^{3}$, em que o texto constitucional traz garantias que visam o controle e limitação da atuação estatal, objetivando impossibilitar novas ditaduras. E mais importante, a Constituição passa a prever mecanismos para a efetivação dos direitos dos cidadãos.

Nesse contexto são crescentes os estudos no sentido de definir o processo constitucional, não mais sendo o processo um instrumento do Estado usado para a prestação jurisdicional, mas agora o processo passa a ser o espaço jurídico de discussão para a construção da decisão. Em outras palavras, o cidadão deixa de ser mero destinatário da jurisdição e se torna agora participante na construção da decisão.

Nesse sentido assevera Brêtas (2012, p.126):

Com maior amplitude no Estado Democrático de Direito, o povo pode e deve exercer ostensiva e preponderante na resolução dos problemas e questões nacionais, através do plebiscito, referendo, audiências públicas e princípios por meio do Processo Constitucional, pois a Constituição, além da garantia do Devido Processo Legal, assegura as garantias procedimentais do Mandado de Segurança Individual e Coletivo, Mandado de Injunção, Habeas Data, Ação Direta de Inconstitucionalidade, Ação de Revisão de Enunciado de Súmula Vinculante, além de Ação Popular visando a anulação de atos estatais lesivos.

Nesse sentido é preciso afirmar que o Processo Constitucional se faz pela participação do jurisdicionado, não apenas nas ações constitucionais, mas principalmente pela observação dos princípios constitucionais em qualquer processo, a saber: contraditório, isonomia e ampla defesa, sendo a participação dos jurisdicionados a forma de legitimação do processo, uma vez que essa participação se traduz em exercício da cidadania, em que os jurisdicionados exercem seus direitos fundamentais, sobretudo a ampla defesa. Destarte, o processo deixa de ser mero procedimento em contraditório para ser a efetiva garantia de direitos fundamentais; a efetivação desse bloco de direitos fundamentais, garantidos aos jurisdicionados e previstos na Constituição, denomina-se Modelo Constitucional do Processo, ou simplesmente Processo Constitucional. Desse conceito surge também a expressão "devido processo constitucional", no sentido de que o "devido processo legal”, previsto na Constituição, só será legítimo se efetivamente garantir e concretizar os princípios constitucionais no âmbito processual.

É preciso esclarecer que o Processo Constitucional não se refere aos procedimentos previstos na Constituição, tal expressão é mais abrangente e se refere ao processo judicial em

\footnotetext{
${ }^{3}$ Não se defende aqui que exista uma plena democracia, apenas se vislumbra no plano constitucional as garantias essenciais para a existência e manutenção do regime democrático.
} 
harmonia com a Constituição; um processo que não apenas seja instrumento da jurisdição estatal, mas que seja uma afirmação da democracia, um espaço em que o jurisdicionado participe, fiscalize e legitime a atuação do poder público. Nesse sentido esclarece Leal (2008, p.34):

[...] no Estado Democrático de Direito, em sua visão procedimental, não mais se poderia afirmar jurisdição como atividade do juiz no desenvolvimento do poder do Estado [...] mas sim como o resultado necessário da atividade discursiva dos sujeitos do processo a partir de argumentos internos ao ordenamento.

Destarte, é imperioso perceber a importância de se compreender o Processo Constitucional como garantia do exercício da democracia e mantenedor do Estado Democrático de Direito. Sob a ótica constitucional, o processo deixa de ser mero procedimento e se torna uma garantia dada ao cidadão de que ele será ouvido, e que o Estado não terá possibilidade de agir de maneira arbitrária.

\section{0 processo constitucional como garantia do exercício da democracia}

Desde 1988, com a promulgação da atual Constituição e a eleição do Estado Democrático de Direito como modelo, verifica-se a elevação da democracia, a princípio maior, devendo ser observado e garantido seu exercício a qualquer cidadão. Em primeiro lugar é preciso esclarecer a diferença entre o Estado de Direito e o Estado Democrático de Direito; o primeiro é todo aquele Estado regido por leis, por um ordenamento jurídico, nesse sentido um Estado totalitário ou ditatorial pode perfeitamente se constituir como um Estado de Direito. Para que um Estado seja Democrático de Direito é necessário que sua legislação assuma a democracia como um princípio fundamental; destarte, não se vislumbra um Estado democrático não constitucional, uma vez que a opção pelo regime democrático deve se dar por uma norma supralegal, sendo essa a diretriz que norteará toda a produção normativa daquele Estado. Assim ensina Del Negri (2011, p.77):

\footnotetext{
Para se admitir um Estado Constitucional e Democrático mister é a presença de procedimentos necessários para a formação racional da vontade, ou seja, um amplo e irrestrito diálogo, no qual todos os participantes tem igual acesso. Nesse aspecto, o ordenamento jurídico emana da soberania popular presente no processo de fiscalidade interpretante do texto constitucional proporcionando condições mais democráticas e legítimas.
}

Em outras palavras, o Estado Democrático de Direito é aquele que permite a participação do cidadão de maneira irrestrita, e para tanto não se vale apenas do ordenamento jurídico, ou seja, da produção legislativa, mas tem como fundamento dessas normas os princípios fundadores da ordem democrática. Nesse sentido preleciona Brêtas (2012, p.124): 
Ao princípio democrático se agrega o princípio do Estado de Direito, este informado por uma gama variada de ideias-mestras que lhe dão contextura, espécies de subprincípios, albergados em normas das modernas constituições que determinam, direcionam, e conformam as atividades do Estado, limitando-lhe o exercício do poder.

Sendo assim, é possível perceber que o Estado democrático de Direito é uma amálgama entre a ideia do Estado de Direito e a Democracia, sendo essa última o princípio mor do Estado, esculpido em sua Constituição.

A Constituição de 1988, em seu artigo $1^{\circ}$ determinou que o Brasil se constitui em um Estado Democrático de Direito; sendo assim, a democracia passa a ser o princípio áureo no Brasil, e a ideia de que o processo é mero instrumento para a prestação jurisdicional do Estado começa a perder força.

Dessa forma a democracia é elevada à categoria de princípio fundamental como esclarece Paollinelli (2016, p.36):

Ora, ao dispor em seu parágrafo único do art. $1^{\circ}$, que "todo poder emana do povo que o exerce direta ou indiretamente por meio de seus representantes", o texto constitucional eleva a democracia à categoria de princípio fundamental, como fonte de legitimação do exercício de poder político pelo povo, entendido como comunidade (sujeito constitucional).

Nesse diapasão é forçoso que se reconheça o direito à democracia como um direito fundamental, uma vez que essa é o princípio fundador do Estado; assim, mais uma vez, se percebe a necessidade de considerar o processo como um espaço do exercício da cidadania, em que as partes são agentes construtores da prestação jurisdicional.

Nesse sentido expõe Theodoro Júnior (2014, p. 53-54):

\begin{abstract}
A Constituição no Estado Democrático de Direito, não se limita a garantir a todos o direito de demandar em juízo. O que se deduz do inciso XXXV do art. $5^{\circ}$ de nossa Carta é que nenhuma lesão ou ameaça a direito deixará de ser solucionada pelo Poder Judiciário, quando provocado pelo interessado, na forma legal. Essa garantia fundamental, portanto, é de uma tutela, ou seja, uma proteção como que se pode contar sempre que alguém se veja ameaçado ou lesado em sua esfera jurídica.
\end{abstract}

Como vemos através da argumentação do douto jurista, o processo não serve como um instrumento ou uma mera relação jurídica; o processo dentro do paradigma democrático se faz uma efetiva garantia de direitos fundamentais, qual seja, o direito de se ter uma tutela jurisdicional devidamente construída nos moldes democráticos e constitucionais, o que também é demostrado nas palavras do mesmo autor:

Essa tutela, destarte, não pode cingir-se a interpretar e aplicar o enunciado de lei pertinente. No moderno Estado Democrático de Direito é imperioso que isto se faça a partir, sempre, dos valores, princípios e regras consagradas pela Constituição. A prestação jurisdicional vai além da exegese isolada do enunciado da lei, para realizar, diante das particularidades do caso concreto, a compreensão e aplicação do 
preceito legal que seja conforme aos mandamentos e garantias da Constituição (THEODORO JÚNIOR, 2014, p.54).

Dessa forma, é possível se perceber a importância do Modelo Constitucional do Processo para o Estado Democrático de Direito, bem como sua natureza garantidora, pois é o respeito aos princípios esculpidos na Constituição que garantem a concretização da democracia.

\section{0 processo constitucional como garantia fundamental e sua inafastabilidade}

A princípio é necessário estabelecer a diferença entre direito fundamental e garantia fundamental, embora alguns doutrinadores considerem a referida diferenciação desnecessária, entende-se a importância dessa uma vez que o próprio texto constitucional a faz. Assim, os Direitos Fundamentais seriam aqueles inerentes ao cidadão, em uma expressão bem resumida e superficial, os direitos fundamentais seriam "a positivação dos Direitos Humanos", em outras palavras os direitos fundamentais constituem direitos do cidadão, direitos inerentes à pessoa, reconhecidos pelo Estado em uma ordem jurídica positivada.

Nesse diapasão, as garantias fundamentais são os mecanismos existentes no Ordenamento Jurídico que visam à efetivação dos Direitos Fundamentais, uma vez que se fazem necessários meios para a efetivação desses Direitos. Nesse sentido, preleciona Brêtas (2010, p.72):

Assim, enquanto os direitos fundamentais são os direitos humanos expressamente
enumerados e declarados no ordenamento jurídico-constitucional, as garantias
constitucionais, por isto, garantias fundamentais, diversamente, compreendem as
garantias processuais estabelecidas na própria Constituição (devido processo
constitucional ou modelo constitucional do processo) e formadoras de um essencial
sistema de proteção aos direitos fundamentais, tecnicamente apto a lhes assegurar
plena efetividade.

Percebe-se que as garantias fundamentais são essenciais para a manutenção da democracia, pois são através das garantias constitucionais que os direitos fundamentais são efetivados e o cidadão é resguardado de arbitrariedades, por parte do poder público ou mesmo de particulares que em benefício próprio poderiam ameaçar ou mesmo solapar direitos fundamentais de seus concidadãos. Ainda Brêtas (2010, p.72) nos afirma que sem as garantias fundamentais “[...] os enumerados direitos fundamentais somente serviriam para aformosear o texto da Constituição ou para revesti-lo de inócuo ornamento retórico".

Uma vez estabelecida a diferença entre direitos e garantias fundamentais, resta a investigação sobre o natureza garantista do processo constitucional, bem como qual ou quais direitos fundamentais ele se presta a efetivar e garantir. Tal questão se mostra relativamente simples de se demostrar, pois é somente através de um processo devidamente estabelecido 
que o cidadão pode exercer seus direitos e ainda se proteger de arbitrariedades. Esse princípio encontra-se expresso no inciso LIV e LV da Constituição, nos quais são previstos o devido processo legal e o direito ao contraditório e ampla defesa respectivamente.

Nesse sentido busca-se demostrar que o processo não deve apenas seguir a letra fria da Lei; necessário se faz que todo e qualquer ato do poder público seja legitimado por um processo, sobretudo os provimentos jurisdicionais, pois são esses a última instância para a resolução de conflitos na sociedade regida pelos princípios democráticos, sendo o processo a garantia fundamental da jurisdição.

Uma vez que o provimento jurisdicional e o direito de ação configuram-se como direitos fundamentais, o processo constitucional se apresenta como a garantia fundamental de acesso a esses direitos; sendo que apenas se atingirá tal finalidade se, e somente se, o processo estiver regido por todos os princípios e normas Constitucionais.

Assim, Brêtas (2012, p.72-73), ao definir a jurisdição como direito fundamental e o processo constitucional como garantia fundamental, assevera:

Efetivamente, jurisdição é direito fundamental de qualquer pessoa, por força de declaração normativa expressa no texto da Constituição, anteriormente apontada. Mas a fruição deste direito se dá pela garantia fundamental do processo constitucional. Logo, considerar que jurisdição, a um só tempo, seja direito fundamental e garantia fundamental, com o máximo de respeito aos que pensam de forma contrária, significa misturar conceitos e olvidar o processo constitucional como garantia fundamental das pessoas.

Dessa forma, pode-se perceber que o processo constitucional tem a natureza de garantia fundamental estabelecida na Constituição da República Federativa do Brasil; assim é imperioso que ao mesmo seja reconhecida todas as características das garantias fundamentais, sobretudo a sua inafastabilidade ou inalienabilidade. Nesse sentido também assevera Brêtas (2010, p.73):

\begin{abstract}
A mais importante das garantias processuais constitucionais é o devido processo legal, que, sob interpretação lógico-sistemática das normas do art. $5^{\circ}$, incisos II, XXXV, XXXVII, LII, LIV, LV e LXXVIII, do art. 93, incisos IX e X, e dos arts. 133 e 134, todos da Constituição Federal, deve ser compreendido como um bloco aglutinante e compacto de vários direitos e garantias fundamentais e inafastáveis ostentados pelas pessoas nas suas relações com o Estado [...].
\end{abstract}

Dessa maneira, é imperioso se reconhecer a impossibilidade de negociação dos atos processuais, uma vez que esses atos são previsões legais e constitucionais para garantir direitos fundamentais. Nesse sentido, se vislumbra uma interpretação equivocada do artigo 190 do Código de Processo Civil, ao se entender possível a negociação de atos processuais, pois como demonstrado o processo constitui uma garantia fundamental e como tal não pode ser objeto de transação. Deve-se observar que o referido dispositivo aborda alterações no 
procedimento; sendo assim, o que se estaria permitindo negociar seriam somente os atos procedimentais.

\section{Atos procedimentais e atos processuais sob a ótica constitucional}

Sobre a distinção entre processo e procedimento Leal (2014), tendo como fundamento a teoria fazallariana, assevera que o processo se caracteriza pela presença da garantia constitucional do contraditório, deixando de ser mero procedimento formal e ritualístico para ser efetivo espaço dialético que propicia a construção do provimento jurisdicional. Assim preleciona o douto jurista para definir o procedimento:

[...] o procedimento é a manifestação estrutural resultante do complexo normativo da positividade jurídica. É a estrutura extraída do texto normativo que a ela é preexistente e que lhe confere legitimidade, validade e eficácia pelo princípio da reserva legal $[\ldots]$ (LEAL, 2014, p.96).

Portanto, é possível perceber que o procedimento é a concatenação de atos que são legalmente previstos, tendo como objetivo formalizar o processo; ou seja, os atos procedimentais são aqueles que possuem natureza exclusivamente formal, não estão imbuídos de nenhuma característica constitucional ou principiológica; são os atos praticados pelo magistrado e servidores com o único objetivo de impulsionar, registrar ou provocar um ato processual, tais como intimações, publicações, redação de atas e outros atos meramente burocráticos visando a autuação (documentação) da atividade realizada pelos sujeitos processuais.

Nesse sentido é que Leal (2014, p.96) afirma: "quando o procedimento não se faz em contraditório, tem-se somente procedimento, não processo". Ou seja, o procedimento é mera sucessão de atos burocráticos; já o processo é um espaço jurídico dialético, em que se promove o debate observando todos os princípios constitucionais, sobretudo o contraditório, a isonomia e ampla defesa.

Embora o já citado autor defina o processo como procedimento em contraditório, respeitosamente afirma-se que a mera observação do contraditório, de maneira formal, no sentido de se oportunizar que a parte se manifeste, não é suficiente. Como demostrado até aqui é necessário que o processo seja desenvolvido com a observância de toda a previsão constitucional, observando os princípios do contraditório, da isonomia e da ampla defesa, princípios que terão vários desdobramentos; uma vez que esses princípios são integralmente observados é que se pode falar em processo, ou em devido processo constitucional.

Logo, é possível se estabelecer a diferença entre atos processuais e atos procedimentais, sendo admitida negociação em relação aos atos procedimentais; mas jamais 
aos atos processuais, pois como se demonstra no presente trabalho o processo é uma garantia fundamental, sendo assim é inalienável.

\section{Conclusão}

É importante frisar que não se está defendendo a impossibilidade de conciliação, ao contrário, a auto composição deve ser vista como um avanço, uma conquista que deve ser preservada, estimulada e aperfeiçoada sempre. Portanto, não se deve confundir a negociação do direito material (auto composição) com a negociação dos atos processuais, evitando a confusão entre os métodos alternativos de resolução de conflitos e o procedimento judicial.

No presente trabalho se pretendeu demonstrar a inviabilidade de se alterar o processo judicial pela vontade das partes, devido sua natureza garantidora e de meio para efetivação de direitos fundamentais. Não pode se admitir que garantias legais e, principalmente constitucionais, seja objeto de transação entre partes litigantes, mesmo que sob supervisão de um magistrado, pois tais garantias têm como objetivo legitimar a atuação do Estado na prestação jurisdicional; sendo tais garantias tão importantes quanto a participação das partes no processo, pois são essas que efetivamente asseguram a participação do cidadão no processo, consequentemente na construção da prestação jurisdicional.

Nesse diapasão, é possível e legítima a negociação de atos procedimentais, que não tenham nenhum eco em princípios constitucionais, tampouco visem à construção do provimento jurisdicional, ou seja, é perfeitamente possível a negociação de prazos (desde que para a ampliação desses, tendo a razoável duração do processo como princípio limitador), a forma de promoção das intimações (abrindo espaço para a tão falada calendarização) e outros atos análogos que visam apenas questões de mero expediente. Portanto, mediante a impossibilidade da negociação dos atos processuais, que são aqueles que efetivamente se pratica visando à construção do provimento jurisdicional, é necessário estabelecer uma interpretação que abarque exclusivamente os atos procedimentais, lembrando que o próprio artigo prevê exclusivamente alterações no procedimento.

Por fim, é preciso afirmar que caso os litigantes desejarem construir de maneira consensual um procedimento próprio para resolução de seu conflito, deverão se valer da arbitragem e não do processo judicial, pois sendo esse o exercício do poder estatal não pode ser alvo de negociação, de alteração, pois o exercício do poder judiciário só é legitimo quando exercido plenamente em observação da lei, e acima de tudo da Constituição. 


\section{REFERÊNCIAS}

BRASIL. Constituição (1988). Constituição da República Federativa do Brasil. Brasília: Senado, 1988. Disponível em:

http://www.planalto.gov.br/ccivil_03/Constituicao/Constituicao.htm. Acesso em: 24 mai. 2016

BRASIL. Lei. 13.105 de 16 de março de 2015. Dispõe sobre o Código de Processo Civil. Diário Oficial da União, Brasília, 16 mar. 2015.

BRASIL. Congresso Nacional. Senado Federal. Comissão de Juristas Responsável pela Elaboração de Anteprojeto de Código de Processo Civil. Código de Processo Civil: anteprojeto / Comissão de Juristas Responsável pela Elaboração de Anteprojeto de Código de Processo Civil. Brasília: Senado Federal, Presidência, 2010. p. 381.

BRÊTAS, Ronaldo de Carvalho Dias. Processo Constitucional e Estado Democrático de Direito. Belo Horizonte: Del Rey, 2010.

BRÊTAS, Ronaldo de Carvalho Dias. Uma Introdução ao Estudo do Processo Constitucional. In: CASTRO, João Antônio Lima; FREITAS, Sérgio Henriques Zandona (Coord.). Direito Processual - Estudo Democrático da Processual idade Jurídica Constitucionalizada. Belo Horizonte: PUC Minas. Instituto de Educação Continuada, 2012.

DEL NEGRI, André. Processo Constitucional e Decisão Interna Corporis. Belo Horizonte: Fórum, 2011.

LEAL, André Cordeiro. A instrumentalidade do processo em crise. Belo Horizonte: Mandamentos, 2008.

LEAL, Rosemiro Pereira. Teoria Geral do Processo: Primeiros Estudos. 12. ed. Rio de Janeiro: Forense, 2014.

PAOLINELli, Camilla Mattos. O que é Processo Constitucional. Âmbito Jurídico, v.19, p. $555,2016$.

THEODORO JÚNIOR, Humberto. Curso de Direito Processual Civil: Teoria geral do Direito Processual Civil e processo de conhecimento. 55. ed. Rio de Janeiro: Forense, 2014. 